\title{
Las Primeras Crónicas Iberoamericanas del Mercure de France (1897-1902)
}

Aunque se han esbozado ya algunos comentarios parciales sobre los corresponsales españoles e hispanoamericanos del Mercure de France, carecemos hasta ahora de un estudio sistemático de las crónicas redactadas por éstos. La salida, con fecha rezagada de 1969, de una sustanciosa monografía de Liliana Samurović-Pavolović, ${ }^{1}$ ha venido a llenar este vacío. Por otra parte, como indica el título de dicho trabajo, no se refiere a las contribuciones brasileñas, imprescindibles para la comprensión completa del conjunto iberoamericano, y aun quedan algunos puntos interesantes que agregar a las observaciones, muy extensas y por lo general muy perspicaces de la profesora Samurović-Pavlović sobre la evolución de la sección hispanoamericana de la revista y el alcance de la misma. Aquí nos proponemos, por lo tanto, ofrecer algunas precisiones sobre las primeras crónicas hispanoamericanas, dar una visión de conjunto de las aportaciones sobre el Brasil hasta 1902, y referirnos oportunamente a lo que hay de contenido hispanoamericano y brasileño en las secciones de letras españolas y portuguesas.

La gran revista parisiense, Mercure de France, cuyo origen se remonta al siglo XVII, había renacido a nueva vida, tal vez más brillante que la anterior, en enero de 1890, bajo la dirección de Alfred Vallette, y gracias en gran parte al vigoroso impulso de Remy de Gourmont la nueva serie alcanzó, como es sabido, una importancia inigualable dentro de las letras francesas, en especial como portavoz del movimiento simbolista. Dedicado al principio casi exclusivamente a las letras nacionales, la nueva serie demoró varios años antes de dar noticias de lo que pasaba en otras lenguas que no fuera la francesa. Incluso las traducciones de

1 Les Lettres Hispano-Américaines au "Mercure de France" (1897-1917) (Filološki Facultet Beogradskog Univerziteta, Belgrado, 1969). La Sra. Samurović-Pavlović publicó un anticipo de su estudio; que fue una tesis doctoral aprobada en la Sorbona en 1966, en la Revista Iberoamericana, 63, enero-junio, 1967, pp. 71-84, bajo el título de "Enrique Gómez Carrillo, redactor de Lettres Espagnoles en el Mercure de France (1903-1907)". 
obras extranjeras en estos primeros años fueron mínimas, y en el caso de las letras luso-hispánicas se reducen a una sola: del poeta simbolista portugués, Eugénio de Castro, muy ligado por cierto a Francia, apareció en enero de 1895 (Vol. 13, núm. 61, pp. 42-46) una traducción en prosa de Hermafrodite. Hay que reconocer, por otra parte, la evidente prioridad que tenía Portugal frente a España, si bien no frente a Hispanoamérica, en lo que concierne a la renovación poética modernista.

Sólo a partir de abril de 1896 (Vol. 18, núm. 76), cuando se inauguró la sección analítica Revue du mois, empezaron a aparecer, tímidamente y muy de tarde en tarde, secciones de unas pocas páginas dedicadas a las letras extranjeras. Primero entre ellas vienen las Lettres italiennes (abril de 1896), del mismo Remy de Gourmont. Es curioso notar que el interés por Eugénio de Castro aparezca inesperadamente en dichas "letras italianas" con una traducción de Belkiss del poeta portugués, al mismo tiempo que se proclama, con presuntuoso engreimiento, la superioridad del francés como lengua literaria:

Il suffit de mentionner la Belkis ( sic) italienne. M. Pica a fait préceder d'une étude sur le poète cette version que recommande le nom du traducteur. Mais c'était peut-être en français qu'il fallait traduire, puisque le français est décidément, aujourd'hui plus que jamais, la langue littéraire européene (p. 150).

Luego se incorporan secciones de "letras inglesas" y "letras portuguesas", (mayo de 1896), ésta última dedicada exclusivamente a Sagramor de Eugénio de Castro. De esta contribución y de todas las sucesivas sobre literatura portuguesa el autor es Philéas Lebesgue. ${ }^{2}$ A partir de junio de 1896 el tamaño de la revista se aumentaba a casi 200 páginas cada número; así se agregan otras secciones de letras extranjeras; la alemana (septiembre), la holandesa (diciembre) y la noruega (julio de 1897), pero la portuguesa sigue siendo la única ibérica hasta octubre de 1897 (Vol. XXIV. núm. 94), cuando otro gran aumento de páginas - hasta 320 cada número - permite un más amplio desarrollo de estos reportajes tan interesantes. Entre las nuevas Lettres portugaises publicadas en este período, si bien continúa sobresaliendo la atención puesta en Eugénio de Castro (octubre de 1896, febrero de 1897), la contribución de abril de 1897 (Vol. XXII, núm. 888) está dedicada a la poésie brésilienne. Así entra Iberoamérica por primera vez, si bien indirectamente, en la consideración del Mercure de France.

En octubre de 1897, en el primer número del nuevo tamaño aumentado, aparecen las primeras Lettres latino-américaines, ${ }^{3}$ debidas a la pluma del

${ }^{2}$ 1869-1958. Figura menor en los círculos simbolistas. Contribuyó, en 1917, con un prólogo al libro de Contreras Les écrivains hispano-américains et la guerre européene.

3 Resulta en este caso equivocada la afirmación hecha en el documentadísimo estudio de Boyd G. Carter, Historia de la literatura hispanoamericana a través de sus revistas (México 1968), im. prescindible para el estudio de las publicaciones periodísticas de Hispanoamérica: "La sección "Lettres Hispanoaméricaines", que se inició en 1890, se publicó con algunas interrupciones hasta 
escritor venezolano Pedro-Emilio Coll. Esto ocurre cinco meses antes de la publicación de las primeras Lettres espagnoles, redactadas por el francés Ephrem Vincent, en marzo de 1898, en el mismo número en que se publica la tercera crónica latinoamericana de Coll.

Nacido en Caracas en 1872, Coll ${ }^{4}$ había sido fundador, con dos amigos, de la revista Cosmópolis. Incorporado luego al cuerpo diplomático, fue destinado a Southampton, Inglaterra. Durante el viaje por Francia para encargarse del consulado, entabló relaciones con el Mercure.

En 1897 hice mi primer viaje a Europa como Cónsul en Inglaterra. De tránsito por París fui fundador y redactor de la sección de letras latinoamericanas en el Mercure de France. Reinaba a la sazón la fiebre simbolista y allí conocí a escritores franceses cuya fama comenzaba a extenderse por nuestra América, influyendo en sus movimientos literarios. Allí Mme. Rachilde, esposa del hospitalario director de la famosa revista, muy burguesa en su hogar y diabólica en sus novelas (dualidad frecuente en algunas escritoras) ${ }^{5}$ nos obsequiaba con copas de Jerez y delicadas golosinas. ${ }^{6}$

Por otra parte, es interesante la prioridad de la sección hispanoamericana. Corresponde, sin duda, a la actitud de la redacción de la revista, sobre todo de la Remy de Gourmont, ${ }^{7}$ quien al ensalzar la nueva literatura hispanoamericana y ostentando a la vez un soberano desprecio por España, no deja de manifestar un mal disimulado afán de imperialismo literario francés en el Nuevo Mundo. ${ }^{8} \mathrm{Al}$ mismo tiempo esta prioridad apenas traicionaba la realidad literaria, tal como se

1940" (p. 19), aunque después dice, correctamente, que Pedro-Emilio Coll la tuvo a su cargo en 1897 1898. Igual pasa con el útil libro de John M. Fein, Modernismo in Chilean Literature: the Second Period (Duke University Press, 1965): "The 'Lettres Hispanoaméricaines' section of the Mercure had been in existence since $1890 . . . "$ (p. 101), aunque el autor también rectifica al referirse correctamente, en la p. 105, a las contribuciones de Coll desde octubre de 1897 a diciembre de 1898 .

${ }^{4}$ La edición póstuma de El paso errante (Caracas, 1948), p. 11 y ss., incluye varios datos bibliográficos. Coll murió en 1947.

5 Mme. Marguérite Eymery Rachilde (1860-1953), novelista que trató de temas sensacionales y esposa de Alfred Vallette.

${ }^{6}$ Declaraciones del propio Coll recogidas en El paso errante, p. 24.

7 La intervención directa de Remy de Gourmont en favor de la sección hispanoamericana parece cierta. Véanse Karl D. Uitti, "Remy de Gourmont et le monde hispanique", Romanische Forschungen, LXXXIV (1960), pp. 51-88 y L. Samurović-Pavlović, op. cit., pp. 105-06.

${ }^{8}$ Véase el prefacio que puso Gourmont a Las sombras de Hellas de Leopoldo Díaz (1902), que provocó una brava controversia en España e Hispanoamérica, sobretodo con Unamuno; véase mi artículo "Unamuno and the younger writers in 1904", Bulletin of Hispanic Studies, XXXV (1958), pp. 83-100, revisado y recogido en Niebla y Soledad: aspectos de Unamuno y Machado (Madrid, 1971). Más tarde, Gourmont tradujo La gloria de Ramiro (Edition "Mercure de France", 1910), publicando un fragmento, "Un autodafé à Tolède" en el Mercure del $1^{\circ}$ de marzo de 1910. Dada la orientación del escritor francés, resulta extraña la selección de una novela que trata de la España del siglo XVI. Por otra parte, se ha dudado mucho de si tenía un dominio adecuado del español para emprender tales tareas. Véase el art. cit. de Karl D. Uitti, Romanische Forschungen, LXXIV (1960). 
veía en 1897 , sobre todo cuando se toma en cuenta la orientación más bien poética y además simbolista del Mercure. Es el momento en que se ha lanzado, fuerte y orgullosa, una nueva promoción de poetas hispanoamericanos, poetas que se sienten por fin espiritualmente emancipados de la cultura española y anhelan aproximarse a Francia, país que por su evidente dinamismo artístico les abre brillantes perspectivas renovadoras. En España, en cambio, no veían los hispanoamericanos otra cosa que una evidente decadencia poética, la turbia política y la hueca oratoria de la Restauración, unidas al rígido casticismo lingüístico de un Valbuena o un "Clarín”. En la península ni siquiera a un escritor como Galdós se le apreciaba en su verdadera altura. ${ }^{9}$ Los nuevos valores, por su parte, no habían dado todavía señales de vida. Es, por lo tanto, perfectamente explicable que un joven escritor hispanoamericano, escribiendo además en Francia, exprese en términos contundentes su hostilidad frente a la tradición española, a la vez que se siente íntimamente implicado en la in. surrección cubana. Es esto lo que proclama Coll en su primera crónica, en la que se funden las dos reacciones, la política y la literaria, contra España.

Les premiers symptômes de l'insurrection cubaine ont coincidé avec un mouvement intellectuel commun à presque toute l'Amérique latine....

Emancipées du joug colonial grâce aux efforts de Bolívar, de San Martín et de tant d'autres héros, assez oubliés et presque méconnus par les historiens européens, ces jeunes nations ont vu l'Espagne s'efforcer de les maintenir sous l'empire de ses dogmes littéraires: mais le cadre de son langage et de sa littérature était trop étroit pour une race qui voulait étendre ses émotions selon l'impulsion de son propre tempérament.

Insiste a continuación en la radical diferencia de raza entre españoles e hispanoamericanos, a la vez que explica la aproximación de éstos a los franceses por inquietudes $\mathbf{y}$ aspiraciones comunes:

La psychologie de notre race, en effet, diffère essentiellement de celle de la race espagnole: l'Européen, l'Indien et le Nègre ont apporté des éléments divers à notre moi; dans chaque globule de notre sang, se répètent les batailles séculaires que se sont livrées ces trois races....

Aussi notre esprit a-t-il ressenti une vive sympathie, malgré les obstacles de la langue, pour les littératures qui révèlent une sensibilité plus inquiète, une vie intérieure, plus troublée par les problèmes modernes et par la lutte pour l'existence: la littérature française contemporaine, par exemple, qui a atteint cet état par d'autres causes que la nôtre.

Finalmente vuelve otra vez a la doble reacción antiespañola, y naturalmente no falta el nombre de Martí como prototipo de ambas tendencias:

9 En su "Examen de conciencia", Cosmópolis, núm. 2, 15 de mayo de 1894, en el que habla de sus amplias simpatías literarias, Coll incluye entre ellas-es el único escritor español-al "irónico Pérez Galdós". Años más tarde, como representante de su país en Madrid, se apresura a ponerse en contacto con el ya anciano novelista. 
Je dois à cette occasion rappeler le nom du grand José Martí, qui peut bien être le symbole vivant de cet état d'âme: il fut tout ensemble l'infatigable amant de la liberté de Cuba et le délicat artiste que propagea une esthétique libre, secouant la poussière des dictionnaires et des grammaires, rompant avec les vieilles formules de rhétorique, donnant à la prose la clameur profonde de nos fleuves et faisant des vers radiants comme l" "étoile solitaire". (pp. 303-305)

La Sra. Samurović-Pavlocić censura la exaltación antiespañola de Coll y de Díaz Romero, ${ }^{10}$ no apreciando claramente quizá lo que pudo haber de sano y natural-si bien evidentemente exagerado - en esta actitud, especialmente en el caso de Coll, en quien no hay que tomar como absolutas o definitivas estas afirmaciones circunstanciales.

Es curioso notar que cuando Unamuno, en abril de 1899 , se refiere a unas quejas, que atribuye a Rubén Darío, de que París no hace caso a los literatos hispanoamericanos, confundiéndolos con los rastaquouères, el autor de estas quejas resulta ser, no Rubén, sino Pedro-Emilio Coll. ${ }^{11}$ Poco después, los dos escritores-Coll y Unamuno-entran en una relación epistolar que va a durar toda la vida; por suerte, esta correspondencia proporciona interesantes datos sobre las opiniones de Coll en años sucesivos. Como ha señalado el Prof. García Blanco, ${ }^{12}$ Coll publicó, a poco de su regreso a Caracas, varios párrafos de una carta de Unamuno en $E l$ cojo ilustrado. Interesa observar que en su carta Unamuno combate, con estudiada moderación, la influencia francesa, a la vez que encuentra en los literatos hispanoamericanos aspiraciones vitales superiores a las de los españoles:

Con todo lo turbio que hay en las actuales letras americanas se ve que aspiran a algo cada vez más alto, que es el "excelsior" su divisa, que no se duermen en el rutinarismo que aquí impera, ni, como nosotros, se jactan de un equilibrio engañoso de salud gañanesca. Si le he de ser franco, me duele algo de la influencia casi exclusiva que la actual literatura francesa allí ejerce, pero ello tiene su razón: la nuestra no puede influir porque no da sustancia.

Publicada esta carta, Coll escribe a Unamuno enviándole un ejemplar de Palabras. Unamuno, por su parte, reseña El castillo de Elsinor. ${ }^{13}$ Le critica discretamente su afrancesamiento y rectifica el aserto de Coll de que el suelo crea las razas, alegando, unamunianamente, que la lengua es la raza espiritual, la sangre del espíritu. Un año más tarde, Coll envía al catedrático salmantino una

10 op. cit., pp. $14-20$ y 35-45.

11 América y Unamuno (Madrid, 1964), p. 56. Sobre el término rastaquouère y los franceses, véase Rufino Blanco Fombona, Letras y letrados de Hispanóamérica(Paris, 1908).

12 'Escritores venezolanos amigos de Unamuno', en América y Unamuno, pp. 167-81. Véase también J. C. Chaves, Unamuno y América (Madrid, 1964), pp. 219-22.

${ }^{13}$ La Lectura, junio de 1902; Obras completas (Aguado), VIII, pp. 168-72. Años más tarde, cuando Coll representó a su país en Madrid, se hicieron buenos amigos. 
especie de bibliografía espiritual en la que cita los nombres de los autores que más le han impresionado:

Autores que escriben hoy lo que yo quisiera decir a veces: Unamuno, Barrès, Lemaître, Anatole France, Valera, Grandmontagne. Mis clásicos: Luciano, Goethe, Montaigne, Gracián, Carlyle, Stendhal, Heine, Larra, Renan, Kempis. Muertos que llora mi inteligencia: Ganivet, Verlaine, Whitman, José Asunción Silva, Casal, Gutiérrez Coll. Viejos amores: Hugo, Tolstoy, Spencer, Daudet, Goncourt. Amores nuevos: Nietzsche, Gorki, Merejkowsky, Ibsen, Gourmont.

Entre estos escritores de todos los países-Coll se jacta siempre de ser cosmopolita-predominan los franceses, pero, al recordar cinco nombres, no faltan completamente los españoles: aparte de algunos simbolistas franceses y modernistas americanos la lista resulta acentuadamente intelectual y filosófica.

El ingreso en las páginas del Mercure, pues, representó para los jóvenes escritores hispanoamericanos un éxito resonante y una gran opertunidad de difundir ampliamente la nueva literatura; por otra parte, cabe señalar lo reducidas que eran estas crónicas tenidas en tanta estima, dentro del conjunto de la revista. Aún si las crónicas hispanoamericanas hubieran sido regulares-la culpa de esto reside indudablemente con los corresponsales y no con la redacción de la revista - no pasarían de ser una media docena de páginas cada tres meses: menuda concesión a una flamante y vigorosa literatura que pretendía ante todo seguir el rumbo estético trazado por los grandes parnasianos y simbolistas franceses, cuyos órganos de publicidad por su parte-ya se quejarán de ello algunos redactores - apenas se dignaban prestarles la menor atención.

De hecho, en el curso de quince meses, de octubre de 1897 a diciembre de 1898, Pedro Emilio Coll publicó siete crónicas "latinoamericanas"(que fueron,en rigor hispanoamericanas), mientras que salieron cinco crónicas españolas y seis portuguesas, una de éstas dedicada, como continuación a la anterior sobre poesía brasileña, a la novela de aquel país, y otra a las relaciones luso-brasileñas. A partir de entonces se silencian abruptamente las crónicas hispanoamericanas, y durante casi dos años y medio no hay ninguna sección de letras de Hispanoamérica. En cambio, durante esa época surgió un ya independiente apartado brasileño, el de Alberto Figueiredo Pimentel, quien redactó su primera crónica en febrero de 1901, seguida por otra en junio del mismo año; por desgracia, tampoco estaba destinado a durar mucho tiempo. Las letras españolas y portuguesas, en cambio, siguieron saliendo sin interrupción durante este periodo, publicándose seis españolas en 1899 y tres portuguesas en cada uno de estos años.

No correspondió evidentemente esta laguna en la sección hispanoamericana a ninguna intención malévola o deliberada por parte de la revista: los redactores de ésta tenían indudablemente más interés en la América Latina que en España. La explicación se encuentra, más bien, en la carrera diplomática de Coll. Según el 


\begin{abstract}
"itinerario biográfico" proporcionado por Mario Briciño-Iragorry, ${ }^{14}$ Coll regresa a Caracas en julio de 1899, lo que explicaría más o menos bien la súbita interrupción de las crónicas a partir de diciembre del año anterior. Lo que no podemos esclarecer es la razón por la cual no se encontró otro corresponsal antes de mayo de 1901, cuando por fin Eugenio Díaz Romero ${ }^{15}$ se encargó de la sección, que ahora se titula, con más propiedad, Lettres hispanoaméricaines. Es el momento de la defunción del El mercurio de América argentino, "la más valiosa de las revistas que produjo el modernismo". ${ }^{16}$ No deja de ser irónico el hecho de que en el momento de desaparecer el máximo esfuerzo por imitar y transplantar la gran revista parisiense a América el director de la revista difunta se haga corresponsal del modelo francés. $Y$ es de notar que no pararon aquí ni mucho menos las tribulaciones de la sección hispanoamericana, pues en ocho años Díaz Romero no ofreció más de 13 crónicas; en algunos años no hubo aportación alguna. ${ }^{17}$ Sólo cuando el escritor chileno Francisco Contreras ${ }^{18}$ emprendió la tarea en 1911 empezaron a disponer los lectores del Mercure de un reportaje sostenido y continuo de los acontecimientos literarios del Nuevo Mundo de habla española. En cambio, las letras españolas seguían vigorosas (12 crónicas en los años referidos, 1901 a 1904); el guatemalteco Enrique Gómez Carrillo ${ }^{19}$ sustituye a Ephrem Vincent a partir de noviembre de 1903. En cuanto a las contribuciones luso-brasileñas, la sección portuguesa, siempre bajo la dirección de Philéas Lebesgue, aparece con regularidad (11 crónicas entre 1901 y 1904), mientras la brasileña, después de 4 crónicas muy espaciadas, desaparece por mucho tiempo en agosto de $1902 .^{20}$
\end{abstract}

Entremos ahora en un examen más detallado de estas crónicas iberoamericanas. Ya hemos citado el comienzo de la primera crónica de Coll en la

14 El paso errante, p. 11.

15 ; 877-1927. Poeta modernista argentino de poca envergadura, su dirección de El mercurio de América dio excelentes promesas - apenas realizadas-de contribuir decisivamente en el Mercure parisiense.

16 H. R. Lafleur, S. D. Provenzano y F. D. Alonso, Las revistas literarias argentinas (1893-1960) (Buenos Aires, 1962), p. 28. A continuación dicen los autores que "Ingenieros, Luis Berisso, Lugones y Díaz Romero se encargaron de comentar, en todas las entregas, la actualidad bibliográfica mundial, en crónicas que asombran...por la madurez del juicio y la amplitud del conocimiento..." (p. 30). En julio de 1901, escribió Díaz Romero a Rubén Darío: "He suspendido la publicación de El mercurio de América desde principio de año. La recompensa no respondía al sacrificio. Es una gran lástima. El Mercurio era la única revista buena que tenía América. Pero ni aún así ha sido posible sostenerla" (p. 31).

17 En 1901, redactó dos reportajes; en 1902 dos; uno solo en 1903; dos en 1904; tres en 1905; uno en 1906; ninguno en 1907; y dos en 1908, ambos en enero. (En su lista de las crónicas, la Sra. Samurović-Pavlović omite la de febrero de 1902, op. cit., p. 166).

18 Para un amplio comentario sobre la aportación de Contreras, en verdad muy sólida, véase el libro citado de John Fein.

19 Véanse el libro y artículo citados de L. Samurović-Pavlović; también, John Kronik, 'Enrique Gómez Carrillo: Francophile Propagandist', Symposium, XXI (1967), pp. 50-60 y Donald F. Fogelquist, "Enrique Gómez Carrillo", en Españoles de América y americanos de España (Madrid, 1968).

20 Se reanudó la sección brasileña en 1910 , y a su cargo estuvo Tristão da Cunha. 
que, a modo muy típico de la época, relaciona la insurrección cubana con la lucha de los nuevos escritores americanos por emanciparse de las anticuadas tradiciones castellanas y donde ve en José Martí el punto de coincidencia de estos dos movimientos, político y literario. Luego lanza una dura crítica contra los dos consagrados enemigos académicos procedentes de la vieja España: "Clarín", con sus intransigentes criterios lingüísticos, y Valbuena, el archipedante de los ripios ultramarinos, con más justicia en el caso de éste que en lo que se refiere al autor de La Regenta. A continuación describe las revistas literarias que de súbito habían brotado en toda Hispanoamérica, fijándose especialmente en Buenos Aires, donde se refiere, entre otros, a Rubén Darío, "le Nicaraguais cosmopolite qui a voulu introduire dans la rime et le mètre espagnols les récentes innovations faites en d'autres langues, la chantre lyrique d'Azul que le peintre Schiafino nous montre décapité au frontispice de son dernier livre" (p. 305); y en Caracas, adonde subraya la importancia de Cosmópolis, que el mismo Coll fundó con Pedro César Domínici y Luis Manuel Urbaneja Achelpohl en mayo de 1894. A pesar de durar muy poco tiempo, la revista tuvo destacado valor dentro de la evolución del modernismo ${ }^{21}$ y Coll nunca dejó de enorgullecerse de su participación en la empresa. ${ }^{22}$ Incluso durante su breve existencia de catorce meses Cosmópolis sufría varios altibajos. Salieron quincenalmente seis números; luego sólo apareció una vez al mes. En el número 9, octubre de 1894, Coll se despide, por razones no explicadas, de sus dos compañeros, pero en el próximo número, que tardó siete meses en salir, en mayo de 1895 , figura ya como único director. En el manifiesto que encabeza este número Coll abre cordialmente las páginas de la revista a todos los hispanoamericanos, y este manifesto lo reproduce en parte en la crónica del Mercure. Su buena voluntad no podía impedir, sin embargo, que la revista muriera dos meses más tarde, con el número 12, en julio de 1895 . Poco más de dos años más tarde, en su crónica parisiense, cree, no obstante, en el progreso realizado en los últimos años y aduce como ejemplo la concesión del premio de la Asociación Venezolana al libro Sensaciones de viaje de Manuel Díaz Rodríguez.

Se refiere después a los cuatro grandes poetas americanos prematuramente muertos, Martí, Gutiérrez Nájera, Julián del Casal y José Asunción Silva ${ }^{23}$ y cita in extenso una necrología de este último en que se refiere a una visita que hizo al poeta colombiano en Caracas y que había publicado con anterioridad en

\footnotetext{
21 "La revista Cosmópolis, mencionada por muchos, pero poco conocida y de difícil consulta, se debe considerar como una de las más importantes del modernismo, primera época", Boyd Carter, op. cit., p. 41. Debo mi conocimiento directo de Cosmópolis a la gentileza de mi buen amigo Pedro Grases, autor, además de un importante estudio de la revista: En el cincuentenario de "Cosmópolis" (Caracas, 1944).

22 Léase, por ejemplo, el artículo "Cosmópolis" de Palabras, 1896, recogido en Pedro-Emilio Coll (Clásicos Venezolanos 14, Caracas, 1966), pp. 102-11.

23 Repárense en cómo salen juntos estos cuatro nombres, precursores o iniciadores-frente a Darío-del modernismo. No entra en nuestro propósito meternos en la polémica sobre el papel respectivo de estas figuras sefieras.
} 
Palabras. ${ }^{24}$ Finalmente afirma, en lo que parece ser un extraño arranque de tardía ilustración setecentista, que el renacimiento literario de la América latina, por deficiente que fuera en ciertos aspectos por razones sociales y políticas, de seguro contribuirá a elevar el espíritu moral y a purificar las costumbres: no son éstas por cierto las cualidades que se suelen asociar con el modernismo. Ve sobre todo al Nuevo Mundo Hispánico como "un immense laboratoire de sociologie où les races diverses s'amalgament, où se produisent les crises les plus étranges de l'Energie et les defaillances les plus mystérieuses"' (p. 309).

En sus crónicas Pedro-Emilio Coll revela ser un hombre muy fino y de extensas lecturas, orgulloso en su panamericanismo, pero moderado e inclinado al eclecticismo y a la conciliación. Como escritor fue muy poco prolífico ${ }^{25}$-para no decir perezoso - y no es extraño por tanto que aproveche otra vez un escrito, ya publicado en Venezuela y que se encuentra en Palabras ${ }^{26}$ para constituir la integridad de su segunda crónica de enero de 1898: es una amplia reseña de las obras Sensaciones de viaje y Confidencias de Psiquis de su compatriota Manuel Díaz Rodríguez.

En la tercera crónica, de marzo de 1898, sale una descripción más detallada de Rubén Darío, la que tiene cierto interés tanto por su fecha todavía temprana como por la condición bastante objetiva de Coll. Dice así:

Dans nos républiques latinoaméricaines, où les militaires et les meneurs politiques avaient seuls réussi à réunir autour d'eux un certain nombre d'hommes plus ou moins intéressés, le cas de Rubén Darío est un augure de temps meilleurs. Darío poète a groupé autour de son oeuvre bien des esprits et a provoqué dans ces régions un des plus vastes mouvements littéraires que se soient produits en Amérique. Les uns le suivent pas à pas, portant son royal manteau d'orient; les autres l'accompagnent jusqu'au gracieux jardin de son $A z u l$ et l'abandonnent à l'entrée du bois taillis de ses dernières oeuvres il y en a qui le repoussent rudement et prennent un chemin définitif, l'antipode du sien, mais chez tous il éveille le désire de la perfection artistique, le culte de la modernité.

$P .-E$. Coll, pp. 48-50. Coll mantuvo este entusiasmo por Silva durante toda su vida. Al hablar de él en Pombo, Obras completas, II (Barcelona, 1957), pp. 156-60, Ramón Gómez de la Serna se refiere a su predilección por recitar poemas de Silva. Es interesante notar que mientras estuvo de agregado en la embajada venezolana en Madrid, frecuentaba por muchos años la célebre tertulia del Café Pombo y que está representado en el famoso retrato de Solana.

25 Como nota, por ejemplo, Rubén Darío al hablar de sus crónicas en el Mercure en el momento de su regreso a Venezuela, "La caravana pasa", (Obras completas, III, Madrid, 1950): "Espíritu fino y delicado, Coll ha publicado escasamente; pero lo poco suyo conocido nos revela una fuerza mental sobre la mentalidad provisional de nuestra América" (p. 762). De su obra como cronista, dice: "Como crítico, el señor Coll ha dado a conocer, siempre con amable optimismo,jen|sus |revistas del Mercure, la producción intelectual de la América española en estos últimos años" (p. 763). Por otra parte, habla de la sección hispanoamericana como muerta casi definitivamente: "El Mercure abrió la rubrique de letras hispanoamericanas, hoy desaparecida, por un extremado cosmopolitismo" (p. $766)$.

26 P.-E. Coll, pp. 79-84. 
Rubén Darío, qui est du Nicaragua, demeure depuis quelques années à Buenos-Ayres, après avoir parcouru une bonne partie du monde. Il y a publié en un court espace de temps deux livres: Los raros et Prosas profanas. Avant cela, il avait déjà publié Epistolas et Poemas, Abrojos, Rimas; c'étaient pour la plupart des lieds d'une grâce inquiète et melancolique, des strophes qui avaient un pétillement de vin du Rhin, une acidité de raisin allemand. Avec Azul (1888) Dario fit oeuvre de maître. C'est devant l'horizon bleu et radieux de Valparaíso, devant les flots que baignent la côte chilienne, qu'il entendit pour la première fois, nous dit-il, le vers de Hugo qui devait lui inspirer ce livre. (p. 908) ${ }^{27}$

Después de citar la irónica observación de Gómez Carrillo de que todo $\mathrm{Azul}$ no es azul, que todos Los raros no son raros y que en Prosas profanas no hay más prosa que el prólogo, ${ }^{28}$ el cronista da una lista de las figuras descritas en Los raros, acabando con esta observación ligeramente crítica:

Voilà Los raros (les rares) qui Darío propose à l'admiration de la jeunesse américaine dans sa prose triumphale et riche, dans son style cosmopolite et quelque peu "snobbish" par moments (p. 969).

Sobre Prosas profanas tampoco falta cierta nota de censura:

Dans Prosas profanas Darío a réuni quelques-unes de ses dernières poésies: l'admirable Sinfonía en Gris Mayor, digne pendant de la Symphonie en Blanc Majeur de Gautier, le Blason d'une ineffable musique Verlainienne, et le Portico, d'un coloris à la Goya; il y a dans le volume des essais heureux de vers libres, de rimes nouvelles, mais aussi nombre de choses que le poète a dû élaguer.

Sería interesante saber a qué poemas se refiere el cronista venezolano en la última frase.

Luego Coll cita el conocidísimo prólogo de Prosas profanas donde Darío se niega a redactar un manifiesto-bien que el mismo prólogo sí lo constituye-y seguidamente comenta en tono no poco crítico:

Si le décalogue esthétique qu'on demandait au poète était inopportun, cette déclaration si sincère et si hautaine ne l'est car en vérité l'influence de Rubén Darío commence à être défavorable au libre developpement des lettres latinoaméricaines et de plus à Dario lui-même. Pour se soustraire en effet à la foule insupportable des imitateurs, il s'est mis à exagérer sa propre originalité, afin de ne pas rester au niveau de ceux qui ont découvert le secret de sa rhétorique de sa méthode idéologique. (pp. 699670)

27 'Para el tema del azul en Rubén Darío, véanse R. Silva Castro, “El ciclo de lo "azul” en Rubén Dario", Revista hispanica moderna, XXV (1959), pp. 81-95, y 1. A. Schulman, "Génesis del azul modernista", en Génesis del modernismo, pp. 115-138.

28 Según Eduardo Carreño, en unas notas anecdóticas añadidas a la edición citada de $E l$ paso errante, pp. 248-49, fue Remy de Gourmont quien primero advirtió el sentido religioso de 'prosas' en Prosas profanas. 
Nuestro cronista ahora vuelve los ojos hacia tres libros argentinos: Poemas de Leopoldo Díaz, Las montañas del oro del fogoso Leopoldo Lugones y la traducción hecha por Luis Berisso de Belkiss, del ya inevitable Eugénio de Castro. Interesa notar que Coll enlaza el bravo poema de Lugones primero con el Hugo de la Légende des siècles y después con la salvaje naturaleza americana:

On dirait que l'introduction est celle d'un lecteur assidu du Hugo de la Légende des Siècles, mais bientôt sa muse se dégage de toute sujection, maltraitant la rime, culbutant la prose, faisant des noeuds, de périodes et des labyrinthes de phrases, sortant, pour ainsi dire, des bornes de la raison humaine. La mer, les nuages, les arbres et le vent ont une vie féroce dans cet étrange poème panthéiste; le panthéisme de l'auteur n'est ni serein ni harmonieux, c'est le panthéisme d'un poète qui a entendu les bruits inouïs de nos fleuves et de nos forêts vierges. (p. 670)

A continuación de una breve descripción de La vida nueva del "esprit distingué" que es José Enrique Rodó y entonces trata de Almas y cerebros de Enrique Gómez Carrillo, quien por su actividad incesante en los círculos modernistas de París y Madrid y su incansable producción de libros no podía dejar de aparecer a cada paso en cualquier comentario contemporáneo. El agudo sentido crítico de Coll descubre en este libro "les mêmes défauts et les mêmes qualités que dans les précédents du même auteur: un dilettantisme sympathique mais superficiel, un louable désir, quelque fois trop marqué, de nous mettre au courant de ses lectures toujours variées et intéressantes" (p. 972). Al mismo tiempo el escritor venezolano se indigna contra el prólogo de "Clarín", que le parece sobremanera desdeñoso, y aprovecha la ocasión para volver a desarrollar, de modo exagerado, como ha indicado la Sra. Samurović-Pavlović, ${ }^{29}$ sus conceptos raciales:

...que le critique d'Oviedo n'oublie pas, premièrement, que la race espagnole n'est pas notre race...; qu'il n'oublie pas, en second lieu, que les individus comme les races obéissent à des lois d'évolution et de développement, que nous traversons une période où, par instinct de conversation, nous avons besoin de manger des idées, et que ne les ayant pas toujours trouvées en Espagne, nous sommes allés les chercher ailleurs. ${ }^{30}$ Aujourd'hui l'assimilation d'éléments étrangers est pour nous une nécessité non seulement esthétique mais sociale. Quand notre organisme aura acquis des forces nous saurons nous créer une physionomie et une vie propres; elles sont d'ailleurs déjà en voie de formation et commencent à se manifester en dépit de bien des critiques et de gouvernements (pp. 972-973).

Finalmente Pedro-Emilio Coll regresa a sus lares para comentar brevemente más libros venezolanos: Verrugas y lunares de Miguel Mármol; Regionales de

30 Nótese el parecido con la carta de Unamuno citada anteriormente. 
José Antonio Espinoza; De mis romerias de Díaz Rodríguez, y termina con las noticias de los premios poéticos otorgados por El cojo ilustrado.

La cuarta crónica (mayo de 1898) continúa el mismo rumbo venezolano de la anterior. Coll describe, como había prometido, la revista El cojo ilustrado, de la que destaca la función internacional que había recogido de la difunta Cosmópolis y la acogida que da a las tres generaciones a la que "d'une manière assez simpliste," - pero con un juicio muy certero, añadiríamos nosotros-sintetiza así:

a) La génération mi-classique et mi-romantique, de tradition espagnole, relativement pure, en grande partie catholique et académique.

b) La génération tantôt romantique, tantôt réaliste, le plus souvent libre-penseuse, préoccupée de politique et à un moindre degré des questions esthétiques.

c) La "nouvelle" génération par les uns appellée "décadente" par les autres modernistes (car en fait d'etiquettes les érudits ne sont pas chiches). Cette génération est plus individualiste que les précédentes, et suivant l'opinion de quelques-uns d'une culture moins solide, mais elle est plus inquiète, plus altérée d'originalité et notoirement influencée par la littérature française. (pp. 636-637)

Tras elogiar esta actitud abierta, "preuve à mon avis d'une grande sagesse", de la revista, Coll da testimonio de una mentalidad alerta y equilibrada al agregar que:

...tout en ètant des "Jeunes", je ne suis pas de ceux qui croient que tout ce que publie la Revue de Deux Mondes par example soit, sans examen préalable, bon à jeter au rebut. Suivant moi, on entend souvent dans les Académies des paroles aussi "nouvelles", aussi profondes que dans nos réunions et nos revues à nous les "Jeunes". S'il est ridicule de croire à l'infaillibilité des cheveux blancs, il ne l'es pas moins de croire à l'in. faillibilité des lèvres adolescentes. (p. 637)

En resumen: "El cojo ilustrado" a été une école de comprehension et de tolérance". En seguida habla de las obras premiadas: Idilio trágico, de Andrés Mata, al que hace el cumplido harto dudoso al afirmar que ciertas estrofas tienen la sonoridad elegíaca de las del gran poeta Núñez de Arce; $L u z$, de Eugenio Méndez Mendoza; Juanito, de Rufino Blanco Fombona, escrito en un estilo pulido, casi clásico, apenas compatible con su temperamento; y finalmente los cuentos de su compañero Urbaneja Achelpohl, a los que elogia por su auténtico sabor americano.

Pasando a otros países, describe las Traducciones del argentino Leopoldo Díaz, y después da un detallado resumen de Del amor, del dolor, del vicio del prolífico Gómez Carrillo, ironizando sobre esta obra franca y deliberadamente inmoral y declarando que se espera de un escritor de su renombre algo más que 
páginas agradables. $^{31}$

La cuarta crónica de P.E. Coll termina con una fina apreciación del entonces joven poeta mexicano Amado Nervo. Transcribo los párrafos esenciales:

Quelles que soient les idées sur lesquelles je ne suis pas d'accord avec Amado Nervo, j'admire l'acte énergique par lequel il a fortement remué, un petit moment du moins, les consciences et les intelligences de son pays. Ses Místicas ont suscité de nouvelles polémiques; un évèque a condamné la circulation du volume de poésies où respire un si ardent catholicisme, où les strophes s'en vont serrées et sèches dans une penombre de cloître. C'est toute l'antique sève espagnole qui a dicté ces vers que l'auteur verse habilement dans un moule moderne. Sur le frontispice on aurait pu graver une copie de la Sainte Catherine évanouie du Sodoma, dans laquelle $M$. Barrès ${ }^{32}$ a vu une des plus vives images de la volupté dans la dévotion. Il y a des strophes en latin et en français, entre autres un hymne grave "A la Majesté catholique de Paul Verlaine". Ce que j'ai cherché inutilement, c'est ce "mal du siècle" dont les critiques ont cru trouver des symptômes dans Amado Nervo. Je crois comprendre que le mal du siècle (qui était déjà le mal du siècle de Hamlet) est cet état de doute où nous sommes au sujet de l'idée individuelle que nous formons du monde; est-ce la bonne? En questions religieuses nous nous faisons la demande de celui qui, agissant d'accord avec la croyance en une récompense future, se dit en lui-même: "Et si en fin de compte il n'y a pas de ciel?"

Il ressort de l'oeuvre littéraire d'Amado Nervo que le "ciel" est pour lui d'une réalité indéniable: ce dont il se défie, c'est de ses forces pour l'atteindre. Sa volonté ne peut s'élever à la hauteur de sa foi, et il s'humilie, et il se sent pauvre et malheureux. En descendant dans les abimes de sa conscience, il se heurte contre les ailes de l'archange déchu, mais non contre le néant, et pour celui pour lequel il y a un là-Bas, il y a un Là-Haut. (pp. 641-642)

La crónica de julio de 1898 es quizás de menos interés. Coll se extiende un poco sobre las razones de la obsesión de la muerte ${ }^{33}$ y la visión tan pesimista de Bernardo Couto Castillo en sus Asfodelos y luego vuelve al tema de la expresión lingüística hispanoamericana; ve la influencia francesa como dañina en cuanto a

31 En un interesante artículo de $E l$ paso errante, Coll habla de la relación poco amistosa entre Gómez Carrillo y José Asunción Silva, compañeros en el naufragio de L'Amérique: "A José Asunción le pareció demasiado 'literaria' la actitud bohemia de Gómez Carrillo, con las mechas al viento, durante el cataclismo, y a mi inquieto camarada Enrique, demasiado espectral, la de Silva, con los brazos cruzados, en el puente del navío que zozobraba..." (Coll, ed. cit., p. 117).

32 En las notas autobiográficas que prologan El paso errante, p. 24, dice que conoció personalmente a Barrès.

33 En la semblanza que envió a Unamuno en 1903 y que hemos citado antes apunta "Cobardía suprema: a la muerte" (M. García Blanco, América y Unamuno, p. 176), cosa que explica este comentario y su interés por Amado Nervo y que evidentemente le enlaza con Unamuno. 
la originalidad, pero considera que aquélla ha prestado una nueva flexibilidad a la lengua:

L'éducation classique et la tradition castillane sont plus faibles en Amérique qu'en Espagne; l'influence française, assez défavorable à l'originalité, a donné aux lettres latinoaméricaines une tournure qui les distingue un peu des lettres de source absolument pure. Don Juan Valera, l'éminent critique espagnol, a pressenti cette différence, il y a des années, en saluant l' $A z u l$ de Darío comme un précieux livre français écrit en espagnol. La prose tend à se faire moins oratoire et plus plastique, le vers plus subtil et plus libre; on martelle moins les consonnes et le rythme ondule et flotte avec plus de grâce autour de l'idée. Pour me servir d'un example, je dirais que dans le vers on joue plutôt des instruments à corde que de ceux de cuivre. Au cri succède le soupir aux clameurs de la multitude les voix intimes. A mon avis cette "évolution" dans la technique correspond à une "évolution" sentimentale: nouveaux états d'âme, nouveaux moyens d'expression. (p. 310)

Por suerte iban a imponerse muy pronto, en España también, los instrumentos de cuerda: piénsese en el 'son de arpa, (el) eco de mandolina' que Rubén Darío supo percibir en la poesia temprana de Juan Ramón Jiménez . ${ }^{34}$

Para Coll la colección Oro y negro de Francisco de Olaguibel pertenece a "cette nouvelle poésie emancée et musicale"... Ciertas composiciones suyas le recuerdan a Julián del Casal, lo que es el máximo elogio que él puede brindar. Luego pasa a hablar del estudio del general argentino Mansilla sobre el dictador Rosas, de Arpegios de Emilio Berisso y de la novela Camila Sánchez del colombiano Abraham López Penha. De este "roman de moeurs américaines" critica el hecho de que todos los personajes discurren en el lenguaje de la época de Cervantes. Finalmente se ocupa del libro de viajes De Bogotá al Atlántico de otro colombiano, Santiago Pérez Triana, más tarde uno de los directores de Helios.

Al principio de su sexta crónica (septiembre de 1898), Pedro-Emilio Coll se revela opuesto a una norma puramente criollista, ostentando otra vez su fino criterio de observador y de psicólogo, que él asocia con Francia:

Bien de gens croient au Nouveau-Monde que l'influence des littératures européenes est un des obstacles à l'avènement désiré de "l'americanisme". C'est-à-dire de la cristallisation esthétique de l'âme américaine et de son objectivation par l'intermédiaire de l'art. Ce n'est pas là mon opinion et $\mathrm{j}$ 'ose même affirmer le contraire. A mon avis, nous devons à l'influence des littératures européenes, et spécialement de la littérature française, un grand perfectionnement des organes nécessaires à l'interpretation de la beauté; nous leur devons les méthodes d'observation, le goût pour ordonner nos impressions. (p. 872) 
Describe una colección de Cuentos mejicanos en los que encuentra que "en général, le ton est ironique et triste quand il n'est pas d'un scepticisme amer" ( $p$. 873). Luego se ocupa nuevamente de un tema extraliterario: las reivindicaciones sociales y humanitarias explayadas en el libro del argentino José Ingegnieros (sic) La mentira patriótica. En seguida, refiriéndose a la poesía de Alberto Ghiraldo, Paris, hace unas sentidas declaraciones sobre la falta de atención que Francia presta a Hispanoamérica:

C'est cet engouement de l'Amérique dont les Français (soyons pratiques, que diable!) n'ont pas su profiter; non seulement les artistes, mais les bourgeois ont les yeux tournés vers la ville de Paris et vers la France: j'ai toujours été surpris de voir l'aveuglement et le dédain avec lesquels la France a répondu aux sympathies de l'Amérique. Car enfin elle n'a pas de motifs de haine ni de ressentiment contre nous.... ...Je pense à l'immense quantité de pouvoir moral et même matériel que la France pourrait exercer dans l'Amérique indolatine et qui lui échappe, grâce à l'ignorance des uns et à la mauvaise volonté des autres.... ...Alberto Ghiraldo me pardonnera d'avoir oublié son poème pour parler de la ville, de la nation que nous aimons, tant, lui et moi, et qui, comme une dame hautaine, méprise l'homme qui est venu des pays du soleil pour baiser le bord de sa robe. (pp. 874-875)

Después de unas observaciones sobre la imposibilidad de ganarse la vida como escritor en Iberoamérica, con referencia al libro De mi diario de Belisario Montes, Coll pasa, en sus séptimas y últimas "letras latino-americanas", a hablar del agudo pesimismo de dos poetas mexicanos, Cirio B. Ceballos, en Croquis y sepias, y los versos de adolescencia de Amado Nervo, Perlas negras. Aunque explica el pesimismo de Ceballos como cosa propia de la adolescencia, concluye (estamos en pleno porfiriato, doce años antes del estallido revolucionario) que "il se produit actuellement au Méxique, avec le progrès matériel, un profond mal'être dans les âmes" (p. 841).

De los "ensayos de modernismo" del uruguayo Carles Reyles explica y enjuicia uno de ellos, el que da título a la colección, El sueño de Rapiña. Con su habitual cosmopolitismo, alaba el libro El pensamiento de América de Luis Berisso por haber franqueado todas las fronteras latinoamericanas: "Si pour les hommes politiques les nationalités continuent d'exister, dans l'esprit d'un nombre considerable d'intellectuels, les frontières ont cessé d'exister..." (p. 842). Se refiere con entusiasmo a la aparición en Buenos Aires de $\mathrm{El}$ mercurio de América, dirigido por Eugenio Díaz Romero, destinado a ser su sucesor como corresponsal del Mercure parisiense. "Les matériaux sont magnifiques. 'Notre revue est d'un caractère éminemment américain', écrit le directeur dans le prospectus". También da la bienvenida a $E l$ sol del domingo, dirigido por Alberto Ghiraldo. Finalmente se queja de que no le han llegado libros ni revistas de los países lindantes con el Pacífico, observación que recoge J. Fein al notar la completa ausencia de libros chilenos tanto en las crónicas de Coll como en las de 
su sucesor Díaz Romero. ${ }^{35}$

Las crónicas de Pedro-Emilio Coll constituyen el esfuerzo más intenso de divulgar la cultura hispanoamericana en la revista europea más prestigiosa de la época; las contribuciones del escritor venezolano fueron, además, inteligentes y perspicaces, sin dejar de manifestar un criterio personal y decidido. Lo que tenían de malo fue que sólo duraron quince meses. Después de su retiro, la sección hispanoamericana seguía con un dinamismo harto reducido hasta que Francisco Contreras se encargó de ella en $1911 .^{36}$

Antes de dejar nuestra referencia a Coll resulta interesante comentar brevemente la larga reseña que su sucesor en la sección hispanoamericana, Eugenio Díaz Romero, hace en diciembre de 1902 de El castillo de Elsinor del escritor venezolano. El nuevo corresponsal lamenta sobre todo la poca fecundidad de éste, característica que, por desgracia, como hemos notado ya, lo va a dominar toda su vida:

Voici longtemps que l'auteur nos devait ce livre. Après la publication de Palabras (Paroles), il s'était emprisonné dans un profond silence d'où rien ni personne ne réussissait à le tirer. Par bonheur pour nous qui le connaissons et l'aimons, il a su vaincre sa paresse et son oeuvre nouvelle marque un progrès évident dans sa puissante individualité littéraire.

Prosigue alabando su rigor ideológico y filosófico procedente de Taine y de Renan, el que contrasta con el excesivo lirismo de tantos jóvenes hispanoamericanos. Es "un peintre et un ironiste de premier ordre...doué d'une admirable pénétration psychologique", pero no tiene las calidades de artista puro y su estilo, justo, conciso y claro, decae cuando intenta expresar la belleza. Advierte también en la obra cierta falta de unidad estructural, pero destaca favorablemente su ensayo sobre el simbolismo americano y sus relaciones con Francia ${ }^{37}$ señalando su "tact ingénieux" y su "haute indépendance mentale".

Durante el período que tratamos había, fuera de la rúbrica de letras extranjeras, alguna que otra manifestación de interés por Hispanoamérica. En la sección Echos de marzo de 1901 (vol. XXXVII, Núm. 135) se publicó una nota sobre "Les droits d'auteurs dans l'Amérique du Sud" en la que se comentó favorablemente sobre la iniciativa de La Nación al publicar, simultáneamente con la primera edición francesa, una traducción española de la novela de Zola Travail: así se dio inmediata difusión de dicha obra en Sudamérica y se suplió la falta de un tratado de derechos de autor entre los dos países. Es evidente que el factor esencial en este asunto es el interés económico de parte de los escritores

\footnotetext{
35 op. cit., pp. 105-06.

36 Contreras fue escogido para el puesto por Remy de Gourmont. Para una relación detallada de su actividad, inteligente y sostenida, véase J. Fein, op. cit., pp. 101-26.

37 "Decadentismo y americanismo", P.-E. Coll, pp. 161-68. El ensayo es importante pero poco conocido dentro de la historia del modernismo. Rufino Blanco Fombona habla de él con entusiasmo en su "Estado actual de la literatura en Venezuela", en Letras y letrados de Hispano-América, pp. 45- 90 .
} 
franceses por penetrar en un nuevo y creciente mercado; pero el Mercure cree conveniente hacer un cumplido al importante diario rioplatense, dando un resumen del contenido del suplemento publicado al iniciarse el nuevo siglo, en cuyas páginas se encontraron codo con codo Remy de Gourmont y Miguel de Unamuno, Max Nordau y Emilia Pardo Bazán.

Interesa notar, además, que Rubén Darío, entonces corresponsal de $L a$ Nación ("envoyé spécial", dice el Mercure) aprovecha la ocasión para ampliar los informes más bien escuetos proporcionados en la nota anterior, en una carta, fechada el 18 de marzo de 1901, publicada en Echos en abril (vol. XXXVIII, núm. 136). En primer lugar, destaca la función del diario en hacer conocer en América el pensamiento moderno europeo:

Non seulement, comme vous l'avez fait remarquer, ce grand organe sudaméricain stimule le mouvement intellectuel national, mais encore il s'est assuré dès le début de son existence, voici plus de trente ans, la collaboration assidue des maitres du journalisme et de la pensée moderne dans les principales nations de l'Europe.

Sobre el caso de Travail, indica oportunamente que no es ésta la primera vez que se hà utilizado el procedimiento de publicación simultánea, que hay en efecto un contracto especial con este fin entre Zola y Daudet y La Nación. Finalmente, subraya la importancia de las ediciones de $L a$ Nación en la vida intelectual sudamericana, señalando especialmente a los autores franceses-entre ellos la Sra. Rachilde y Remy de Gourmont, estrechamente asociados con el Mercure-que habían salido en sus páginas:

Il est un point sur lequel je voudrais insister et c'est le rôle intellectuel joué par "La Nación" dans l'Amérique du Sud. Ouverte à tous les talents, sans distinction d'écoles, elle a contribué dans une vaste mesure au renouvellement des lettres et de la pensée, et, grâce à elle et à ses collaborateurs, les noms de Verlaine, Mallarmé, Moréas, Rachilde, Tailhade, Albert Samain, Mauclair, etc., sont devenus familiers des rives de La Plata aux côtes du Pacifique, et la jeune littérature hispanoaméricaine a dû accueillir la collaboration de $\mathrm{M}$. Remy de Gourmont à ce journal comme celle d'un maître déjà son ami. (pp. 283-284)

Dentro ya de la época de las crónicas de Díaz Romero, y sin duda supliendo en cierto grado la creciente irregularidad de las mismas, el diplomático colombiano Alfredo de Bengoechea publicó, en mayo de 1903 (vol. XLVI, núm. 161), bajo la rúbica de Variétés, un extenso estudio de José Asunción Silva. Importa reparar en que ésta es la única contribución hispanoamericana publicada fuera de las crónicas establecidas, si bien también dentro de la sección analítica, antes de 1906, cuando Leopoldo Lugones contribuyó con un artículo sobre la influencia francesa en Argentina, tema por supuesto no ya desinteresado. ${ }^{38}$

3815 de septiembre de 1906. En 1908 ( $1^{\circ}$ de abril) se publicó el estudio de Ricardo Rojas, "Un poète sud-américain, Rubén Darío". 
El propósito del artículo de Bengoechea es el de reclamar para Silva el puesto más alto dentro del modernismo. No duda en calificarle "du plus séduisant, du mieux doué des poètes hispanoaméricains, de celui que fut en Amérique l'initiateur du mouvement littéraire moderne". Y si reconoce algunas cualidades superiores de vocabulario y de adjetivación en Guillermo Valen. cia-otro colombiano-se debe a que éste ha seguido el ejemplo de Silva. En cambio, Bengoechea se siente obligado a rebajar el mérito de Rubén Darío en favor del que proclama "le plus grand poète qu'ait jamais vu naître encore la jeune Amérique espagnole".

Je n'en dirai pas autant, au risque de m'attirer quelques foudres, de Rubén Darío, dont le tapage fait autour de son nom, je ne sais pourquoi, m'agace. Non que je nie l'incontestable talent de l'auteur des Prosas profanas, la virtuosité très sûre de sa touche, sa patte de maître. Mais ses vers me font toujours l'effet d'emprunts faits au français. J'y découvre trop facilement les sources de son inspiration. Les Parnassiens, les Décadents, les Symbolistes, tout cela se presse confusément dans ses vers qui, je l'avoue, me fait regretter les originaux. Sa langue même fourmille de gallicismes. Rien de tel chez Silva, où l'inspiration, je le répète, reste absolument personnelle. Là est la supériorité de l'auteur de Nocturno, là son incontestable gloire. (p. 572)

En ciertas ocasiones las letras españoles se ocupan de libros o temas hispanoamericanos. En julio de 1898, por ejemplo, Ephrem Vincent se refiere a la polémica entre don Juan Valera y Rafael Merchán sobre el problema cubano en La España moderna. Hay alguna referencia pasajera a Rubén Darío, y constantemente surge el nombre de Enrique Gómez Carrillo, que alternaba su residencia entre París y Madrid y a quien Vincent trata sin vacilación como escritor español. Es de notar que tiene una opinión más favorable de Carrillo de la que hemos apuntado de Coll y que le atribuye precisamente los méritos que los cronistas hispanoamericanos proclamaban como la máxima innovación de sus nuevos escritores: "il a tout fait-dice Vincent-pour émanciper la littérature castillane de ses lieux communs et pour lui donner un peu de grâce aventurière. Il a établi le premier la synthèse de Paris-Madrid". ${ }^{39}$ Por otra parte, Vincent dedica mucha importancia-merecida-a la literatura catalana ${ }^{40}$, la que, como había señalado entre otros Rubén Darío, ${ }^{41}$ tenía en aquella época un empuje modernizante y una vitalidad apenas perceptibles en la literatura castellana peninsular.

39 Agosto de 1901, vol. XXXIX, núm. 140, p. 544.

40 Hay crónicas sobre literatura catalana en mayo de 1899, febrero de 1900, roctubre de 1901 y febrero de 1902. También se da un caso insólito: se publicó en septiembre de 1899 , en las páginas literarias, una traducción de L'alegria que passa de Santiago Rusiñol: es la única traducción hispánica de los años que nos ocupan: L'Allégresse qui passe, traducido por Marius André (vol. XXXI, núm. 117 , pp. 647-83). Marcel Robin, en su primera crónica del $1^{\circ}$ de mayo de 1908 y en la del $1^{\circ}$ de julio de 1909 , se ocupa también de la literatura catalana.

41 Véanse los artículos "En Barcelona" y "El modernismo" en España contemporánea y también Tierras solares [Obras completas, III]. 
Liliana Samurović-Pavlović nota el curioso hecho de que no sólo son hispanoamericanos los que se ocupan de la sección dedicada a la literatura de ellos, sino que la de letras españolas está dirigida por no españoles: primero por un francés, después un hispanoamericano y luego, a partir de 1907, por otro francés, Marcel Robin ${ }^{42}$ La cuestión de nacionalidad en sí poco importa y Gómez Carrillo se consideró-y fue considerado, como hemos visto-como español además de hispanoamericano. Lo cierto es que él no impuso aquella división tan radical entre españoles e hispanoamericanos característica de Coll y Díaz Romero, pero a la vez se reveló más incondicionalmente afrancesado que ellos. Su planteamiento del problema de la literatura hispana moderna no estriba en una lucha entre España e Hispanoamérica sino más bien en una separación de generaciones, entre viejos y jóvenes, entre modernistas y no modernistas, sean españoles o americanos. Esta actitud le valió una notable pendencia con Unamuno $^{43}$ y le animó a llevar a cabo una importante encuesta sobre el modernismo ${ }^{44}$ aspectos que caen ya fuera de nuestro tema. Limitémonos a citar de su primera crónica (noviembre de 1903, vol. XLVIII, núm. 167) las páginas del escritor argentino Manuel Ugarte sobre la influencia francesa, en las que, siguiendo el mismo rumbo galófilo que sus compañeros, traza una distinción justificable, no ya tajante y absoluta, entre las literaturas de España y América:

Le mouvement qui a pour objet de moderniser le castillan vient de source française. Tous ne veulent pas l'avouer en Espagne, mais c'est l'exacte vérité. Abandonnant la solennelle et vague verbosité de l'ancien castillan, tous commencent à céder aux exigences de l'époque, en s'efforçant de donner un peu plus de précision a leurs phrases. Les écrivains hispanoamércains, dont la culture intellectuelle est exclusivement française, ont été les premiers à s'affranchir du purisme et à prendre l'initiative de l'évolution. D'aucuns ont exagéré la tendance et, poussés par leur désir d'innover, écrivirent en un dialecte ridiculement incompréhensible. Mais le temps, qui se charge de mettre toute chose en place, a su apporter un correctif à ces élans passionnés en réduisant la tentative à ses vraies proportions. Il ne manque pas en Espagne, parmi les jeunes, d'auteurs concis et brillants qui tiennent plus à la rapidité de l'expression qu'aux traditions de la forme... Ils ont le désavantage de ne pas contenter les "hablistes" méticuleux qui passent leur existence à pasticher les maîtres anciens; mais ils ont par contre l'avantage d'être

42 Para los detalles de su aportación hispanoamericana, véase L. Samurović-Pavlović, op. cit., pp. 85-87. Rubén Darío se encargó de las Lettres espagnoles en una ocasión ( $1^{\circ}$ de mayo de 1906$)$ para hacer una reseña del libro de Gómez Carrillo De Marseille à Tokio.

${ }^{43}$ Véase mi artículo citado 'Unamuno and the younger writers...', BHS, XXXV (1958), pp. 83 100, recogido en Niebla y Soledad.

${ }^{44}$ Véase Alfredo Roggiano, "El origen francés y la valoración hispánica del modernismo", en Memoria del Noveno Congreso del Instituto Internacional de Literatura Iberoamericana, Columbia University (México, 1962), pp. 22-39, y L. Samurović-Pavlovic, art. cit., pp. 77-80, y ob. cit., pp. 96-99. 
lus par le public avec intérêt. "Nous avons réussi à faire faire au castillan un pas en avant durant ces quinze dernières années", écrit M. Salvador Rueda dans une étude remarquée, en le rendant sanguin jusqu'à la congestion, pittoresque jusqu'à la fidélité du portrait, lumineux jusqu'à l'éblouissement, plastique jusqu'au relief et ailé jusqu'à y dissoudre les idées et à leur donner l'accent de la musique et des choeurs." Et c'est bien là tout d'abord le résultat de l'influence de la littérature française en Espagne. (pp. 549-550)

Es claro que la condición de la literatura brasileña, a finales del siglo pasado, distó mucho de la de las literaturas hispanoamericanas hermanas. Asentadas las letras brasileñas, en las grandes ciudades de la costa, sobre una base social y cultural más estable, se habían desarrollado ya movimientos parnasianos y simbolistas de cierta amplitud y una novelística que además de muchas obras de índole naturalista contaba con una figura tan excepcional como Machado de Assís; Machado aparte, faltóles todavía, en cambio, el estallido de una nueva literatura que se proponía romper decisivamente tanto de sus precursores como de la antigua metrópoli peninsular. Carecen por lo tanto, en general, las crónicas brasileñas de la agitación y del afán renovador que caracterizan a las hispanoamericanas. Además, las contribuciones de Philéas Lebesgue, que por otra parte mantenía durante unos treinta años no sólo la sección portuguesa sino algunas otras (neo-griegas, noruegas), importantes, eso sí, por el digno esfuerzo que representaban, tenían mucho de tentativas e intuitivas. En la crónica dedicada a la poesía (abril de 1897), después de especular sobre la pretendida ausencia de la filosofía ${ }^{45}$ en el Brasil ("la philosophie, pas plus que l'esthétique raffinée, n'est le propre des peuples jeunes", (p. 174) cita varios nombres de poetas de muy diversa inspiración, entre los cuales destaca a Raimundo Correia y a Alberto de Oliveira, ("d'un parnassisme aux visées impersonnelles...le premier avec ses Symphonias, toutes de recherches musicales, le second avec ses Meriodonaes, ( $\mathrm{sic}$ ), aux effets presque exclusivement picturaux", p. 175): estos datos los saca evidentemente de un estudio francés anterior, el de Louis Pilate de Brinn' Gaubast. Sobre la juventud ofrece esta opinión sin dar más detalle: "Les 'tout jeunes', séduits par les magnifiques évocations du beauté pure suscitées par Eugénio de Castro, se laissent entraîner dans le courant esthétique inauguré naguère en Portugal et dont l'origine est, d'ailleurs, toute française".

Las "letras portuguesas" de junio de 1898 tratan de Le roman au Brésil. Lebesgue empieza alabando a los "indianistes romantiques" de otra generación como José de Alencar, J. Manoel de Macedo y Bernardo Guimerães y encuentra que "emigré en Amérique, le génie lusitanien, peu à peu envali d'abstraction dans la métropoli, devait reconquérir l'intégrité de son sensualisme natif et foncièrement lyrique. Tout l'idéal ici se vêt de chair et s'harmonise de vie in-

45 Lt esgue pasa por alto la importancia del positivismo en el Brasil. Véanse J. Cruz Corta, Contric ticão à história das idéias no Brasil(Rio, 1956), y I. Lins, História do Positivismo no Brasil ( $2^{*}$ ed. revisada, São Paulo, 1967). 
tense..." (p. 923). En cuanto a los llamados realistas o naturalistas, apenas diferenciados, enumera atropelladamente una serie de nombres sin definir adecuadamente el naturalismo. En común con todos los críticos contemporáneos, no se da cuenta de lo mucho que separa a Machado de Assís de esta escuela ni de la superioridad que tienen las obras de éste a partir de As memórias póstumas de Brás Cubas; y antepone Coello Neto a Aluísio Azevedo:

Au Brésil comme en France, le naturalisme, ou plus exactement le réalisme, succède au sentimentalisme romantique, et se manifeste avant tout par une recherche plus aigüe dans-l'impeccabilité du style. Ainsi Machado de Assiz est avant tout un ironiste et un psychologue, ce qui ne gâte rien et ce qui n'empêche pas Yaya Garcia, Resurrecçao (sic) d'être des productions hors de pair: Coelho Neto, l'auteur du Roi Fantôme et de l'Hiver en fleurs, est plus que tout autre un fantaisiste et un magicien subtil; c'est déjà un cosmopolite. Aluizio Asevedo, l'auteur de l'Homme, Julio Ribeiro, qui écrivit la Chair, Pardal Mallet, Adolfo Caminha appartiennent plus spécialement à l'école zoliste.

De Inglés de Souza on doit retenir le Missionnaire, et de Valentin de Magalhaes, Fleur de Sang; citons encore Raoul Pompea (sic) et Lucio de Mendonça.

Finalmente se refiere a 'Silvio Dinarte,' de modo algo extraño, como un talento especialmente francés y habla con particular aprobación, entre los jóvenes, de Oliveira Gomes, autor de La nuit; se trata de una relación personal, pues la sección "A noite" de Terra dolorosa (1899) va dedicada a Lebesgue. ${ }^{46}$

También en otra crónica portuguesa, la de febrero de 1899, Philéas Lebesgue discurre sobre el tema de las relaciones luso-brasileñas, subrayando la dificultad que hay en restaurar un cordial contacto entre un pueblo emancipado y su antigua metrópoli; como dice muy justamente , "rien n'est plus difficile qu'une reconquête". Así es que ha habido, en Portugal, según Lebesgue, una ignorancia total del Brasil y existe o ha existido una antipatía mutua entre los dos países. ${ }^{47}$ Los brasileños, por su parte, acentúan deliberadamente sus diferencias raciales y lingüísticas $\mathrm{y}$-cosa curiosa, al revés de lo que ocurrió en el mundo hispánico-existe una fuerte corriente antifrancesa por el enlace que creían ver entre Francia y Portugal. Pero ahora, afirma Lebesgue, éste va aprendiendo más de su antigua colonia y el crítico francés cree que "une étrange corrélation persiste entre les deux tempéraments". Sorprende, por cierto, que no se refiera a Eça de Queiroz y al resonante éxito, que $O$ primo Basílio (1878) consiguió en el Brasil. ${ }^{48}$ En ambos países se sienten influencias diversas, alemana e inglesa,

46 Véase Andrade Muricy, Panorama do Movimento Simbolista Brasileiro (2 ${ }^{\mathrm{a}}$ ed. Rio, 1969, 2 vols), vol. II, p. 533.

47 Véase R. Sayers, “A literatura brasileira no Portugal oitocentista: os críticos, os jornais, as revistas", Garcia de Orta (Lisboa, 1972), pp. 507-25.

48 Véanse J.-M. Massa, "O primo Basilio lu et vu par ses cousins du Brésil", Etudes LatinoAméricaines, Rennes IV [1968], pp. 25-38, y Dorothy Scott Loos, The Naturalistic Novel of Brazil (New York, 1963), pp. 66-72. 
además de francesa, pero como buen poeta y crítico simbolista en ambos ve dominante el esteticismo: "les meilleurs de chaque côté, les plus jeunes surtout, tendent à reprouver la funeste influence des tendances politico-moralisatrices dans l'Art". Sucesivamente habla' de los diversos centros literarios del Brasil: São Paulo, Recife, Río, Bahia, Para. En el de São Paulo, menciona, en compañía de Coelho Neto y otros, al que va a ser redactor de las letras brasileñas, "Figueredo ( sic) Pimentel". De las varias influencias extranjeras concluye que seguirá dominando la francesa: "nous resterons longtemps encore, et principalement pour le monde latin, les initiateurs de l'Art". Y termina expresando la opinión de que el Brasil, si tiende a aislarse de Portugal, no por eso se acerca más a los países de habla española que le rodean: "il est, de par l'affirmation de son tempérament littéraire, individuel et doit rester individuel!"

Unas crónicas de más tarde, en julio de 1901, cuando ya se ha inaugurado la sección brasileña independiente, Lebesgue vuelve brevemente a las relaciones luso-brasileñas, viendo en la publicación en Lisboa de dos libros, Contos de amor y George Marcial, de Virgílio Varzea, un importante síntoma del acercamiento de las dos literaturas.

Alberto Figueiredo Pimentel (1869-1914), que fue autor de novelas sensacionales y escandalosas, ${ }^{49}$ de poemas de tipo decadente y compilador de historias y cuentos para niños, se encargó de una independiente sección de Lettres brésiliennes a partir de febrero de 1901. Comienza su primeral crónica con la obligada queja contra la ignorancia de su literatura en Francia. Sólo existen, dice, dos novelas brasileñas en traducción francesa, el Guaraní de Alencar, ("considéré comme son chef d'oeuvre") e Inocência de 'Silvio Dinarte', pseudónimo del vizconde de Taunay, cuyo éxito Pimentel, tratándole con otro miramiento que Lebesgue, atribuye exclusivamente a los elevados cargos diplomáticos de que disfrutaba su autor durante el Imperio.

Bastante difuso como comentarista, Figueiredo Pimentel emplea una parte excesiva de su limitado espacio en hablar de cosas de poca monta y en citar nombres un poco "au hasard". Da una prolija relación de todo lo que le toca hacer, reparte elogios a su predecesor Lebesgue y al director de la revista y declara su buena voluntad de incluir a todos los que lo merecen. Así escribe en términos extremadamente encomiásticos de Gonzaga Duque, íntimo amigo y compañero suyo: "Parmi les figures de la génération nouvelle l'une des plus suillantes est sans contradit Gonzaga Duque... Par son roman Mocidade morta (Une jeunesse morte) le jeune écrivain fut definitivement sacré romancier et styliste hors de pair. Sa prose est un enchantement, pour l'harmonie, pour la sonorité de la phrase précise, impeccable, pour la propriété du terme presque toujours neuf, souvent inédit..." (p. 563). Después cita su obra como crítico de arte y como cuentista y habla de su novela todavía no acabada Sangravida, que,

49 Para sus novelas, véase D. S. Loos, op. cit., pp. 115-16. Para su poesía, véase la obra monumental de Muricy, op. cit., I, pp. 385-87. 
al parecer, nunca se terminó. A continuación se ocupa de la poesía de Bernardino da Costa Lopes, haciendo un comentario general muy vago: "il vit au sein de la Tour d'ivoire d'un Songe éternal, à travers lequel passent châtelaines et duchesses, pages et grandes dames, hommes d'armes et damoisseaux, toutes scènes et personnages de moyen-âge et de chevalrie" (p. 564); sucesivamente menciona, con menor detenimiento, a Dario Veloso y $O$ Cenáculo de Curitiba, y luego a otros poetas: Mário Pederneiras, Arthur Lobo, citado también como novelista y Alphonsus de Guimeraens, titulado "un croyant de Verlaine". Choca por su ausencia el nombre del poeta simbolista de más significación, Cruz e Sousa, muerto en $1898 .^{50}$ Termina con una breve relación de los principales periódicos y revistas del país.

En su segunda crónica (junio de 1901) Figueiredo Pimentel comenta sobre la fundación, dos años antes, de la Academia brasileña de letras, modelada sobre la francesa y asociada esencialmente, para el autor, con la generación anterior, a que llama, con cierto resentimiento apenas suprimido, "des vainqueurs d'hier, désormais consacrés devant l'opinion publique, de ceux qui accaparent tous les honneurs et dont ne cesse d'occupar la critique" (p. 826). Continúa diciendo que en la Academia hay quienes nunca la tomaron en serio y que si bien la mayoría pertenece a la élite de la literatura brasileña, tres o cuatro hay que no lo son y que media docena no tienen más méritos para ser académicos que el de ser miembros del cuerpo diplomático. Después de enumerar varios cambios, incluida la elevación del conde de Rio-Branco, habla con justo entusiasmo del fundador y presidente vitalicio de la Academia ${ }^{51}$ Joaquim Maria Machado de Assís:

Notre Académie a pour président $M$. Machado de Assís, l'un des plus grands parmis les écrivains du Portugal et du Brésil, considéré tant par les nouveaux que par les anciens comme étant le maître auteur, le chef de la Littérature brésilienne. Machado de Assís a quelque soixante ans, mais il est toujours plein de force...et il continue d'appartenir à la génération actuelle. Son bagage littéraire est important. Il s'en détache avec éclat les romans Memorias Posthumas de Braz Cubas (Mémoires posthume de Braz Cubas) et Quincas Borba, celui-ci continuant celui-là, sans que la lecture séparée de chacun puisse en souffrir ${ }^{52}$

Ce sont deux chefs-d'oeuvre impeccables de style, classiques et modernes tout à la fois, et dont la philosophie humoristique s'apparente à celle de Thackeray et autres écrivains anglais. Mais où Machado de Assis se révèle inimitable et vraiment parfait, c'est dans ses contes.

50 Para el simbolismo brasileño, consúltese Massaud Moisés, O Simbolismo (1893-1902): vol. IV, de A literatura brasileira (Cultrix, São Paulo, 1966).

51 Sobre la Academia, consúltese J. Montello, Pequeno anedotário da Académia Brasileira (São Paulo, s.f.) y O presidente Machado de Assts (São Paulo, s.f.).

52 Es curioso que Figueiredo Pimentel no se refiera a Dom Casmurro, en venta desde los primeros meses de 1900. Las Poesias completas también habían salido ya, en abril o mayo de 1901, demasiado tarde, aparentemente, para esta crónica de junio del mismo año. 
Quelques-uns peuvent être classés parmi les meilleurs que l'on ait écrits. Nous sommes certain que ces contes et les deux romans en question obtiendraient, en traduction française ou autre, un succès colossal. Comme poète, $M$. de Assis est plutôt parnassien. De lui ont paru plusieurs recueils de vers; mais ses meilleurs poésies, les plus récentes, n'ont pas encore été réunies en volume. $M$ ide Assis est un des rares écrivains du Brésil qui vivent a l'écart, loin des "côteries", modestement, toujours au travail et dédaignant la réclame. (p. 827)

De Henrique Coelho Netto discurre extensamente pero con más reservas:

Coelho Netto est le plus fécond de nos écrivains. Ses oeuvres publiées sont nombreuses: romans, nouvelles, contes, poèmes en prose, drames symbolistes, libretti d'opéra, livres d'éducation, articles de journaux, etc. Sa collaboration est quotidienne à différents journaux et périodiques, et les travaux qu'il élabore sont considérables. Cet écrivain, qui n'a pas encore atteint la quarantaine, débuta, il y a vingt ans passés, avec des poèmes en prose, des ballades, des contes et fantaisies aux décors et paysages d'Orient, aux sujets de préférence empruntés à la Bible. Son style fut toujours très élégant, mais plein de néologismes et de termes techniques, qui en rendaient la lecture difficile et même impossible sans dictionnaire. Coelho Netto n'est pas un écrivain original, quoiqu'on ne puisse le qualifier d'imitateur ni de plagiaire.

Se refiere a varias novelas suyas ( $O$ Rei Fantasma, Miragem, Inverno em flor, Pelo Amor!) y concluye no sin justicia:

Son défaut est d'écrire beaucoup et surtout d'écrire sur le genou, au jour le jour, sans laisser pourtant de retoucher, limer, polir la phrase ou la période. (p. 828)

Menos atención le merece Aluísio Azevedo "romancier réaliste...d'une excellente observation...A casa de Pensão...et $O$ Cortiço...sont deux beaux romans pour servir à l'étude de certaines couches de la société brésilienne" (pp. 828-29). Después de referirse brevemente a Artur Azevedo, hermano del anterior, pasa a hablar de Medeiros e Albuquerque, introductor del decadentismo en el Brasil y piedra de escándalo en su tiempo con sus Pecados (1889). De él dice Figueiredo Pimentel que "il était le seul à connaitre Mallarmé, Verlaine, Rimbaud, etc., ce dont il profita pour écrire quelques nouveautés...A cette époque, l'auteur portait collet rouge, et en guise de cravate, une branche de fleurs d'oranger". (p. 829) Ahora, nota con tristeza nuestro cronista, se ha hecho profesor, diputado y periodista, como tantos otros adeptos a la literatura.

Más adelante Figueiredo Pimentel describe brevemente las obras de los tres parnasianos, Alberto de Oliveira, Raimundo Correia y Olavo Bilac, "l'auguste trinité de la poésie brésilienne...adorateurs de la forme et du mot, chercheurs de rimes opulentes", pero en el caso de Bilac se refiere sobretodo a su actividad como prosista. Cita después otros nombres de menos importancia (Luis Murat, Valentim Magalhães), da una lista de críticos encabezados naturalmente por 
Sílvio Romero, Araripe Júnior y Veríssimo, y otra de escritoras en la que Francisca Júlia de Silva figura en primer lugar.

Las terceras "lettres brésiliennes", que tardan once meses en aparecer, corresponden a mayo de 1902. El cronista se disculpa de su silencio explicando que fue responsable "une grave, très grave maladie, dont j'ai souffert durant une grande partie de l'an passé, jusqu'à me rendre toute espèce de travail impossible" (p. 554). Procede entonces a hacer una reseña sobre el movimiento literario brasileño del año 1901, el que considera "importante" dado el desaliento general producido por la aguda crisis económica. El mayor éxito le parece corresponder a los Poemas da Morte de Emílio de Menezes, "poète élégant, de forme achevée, irréprochable, et qui évoque, selon une comparaison déjà usitée par nous ici-même, un José María de Hérédia mystique, d'un mysticisme à la Verlaine. Comme l'auteur des Trophées, il a le souffle court el l'inspiration mésurée" (p. 554).

Luego hace mención de Rondas noturnas de Mário Pederneiras, Hellenos de B. Lopes, "sonnets à sa manière, originaux et magnifiques, 'des lys à quatorze pétales', comme il les appelle" (p. 555), las Palavras que o vento leva del elegante Guerra Duval y $O$ Cavaleiro do Luar de Gustavo Santiago, "sévèrement jugé" por los críticos a causa "des images bizarres ou absurdes" que representan "quelque exagération de symbolisme".

Viene un comentario sobre Machado de Assís como poeta, expresándose en términos más categóricos que los anteriores y dando un juicio peregrino sobre la traducción de "The Raven" de E. A. Poe:

Le maître et prince de la littérature brésilienne, Machado de Assis, l'impeccable styliste, vient de réunir en un seul divers recueils antérieurement publiés, pour en faire une édition définitive, ne varietur. Il a mal fait. Machado de Assis fait des vers d'un rythme sûr; mais il n'est pas, surtout aujourd'hui, un vrai poète. Il lui manque l'émotion, le sentiment.

La meilleure chose d'entre les Poésies complètes, c'est la magnifique, la divine traduction du Corbeau d'Edgar Poe qui est peutêtre meilleure que l'original. (p. 555) ${ }^{53}$

A continuación señala la muerte de Arthur Lobo, "prosateur magnifique et magnifique poète", y de Orlando Teixeira, un mes después de publicar su primer tomo de versos, Magnificat.

De las obras en prosa, menciona brevemente las Historias curtas de Domício da Gama y George Marcial y los Contos de Amor de Virgílio Varzea, publicados como hemos visto, en Portugal. A continuación emite dos críticas generales.

53 Sobre esta traducción, consúltese J. Mattoso Cômara Júnior, "Machado de Assís e o Corvo de Edgar Poe," Revista do Livro, X, (1958), pp. 101-09, y J.-M. Massa, Machado de Assis traducteur (fotocopia del vol. 3 de su tesis, Poitiers, s.f.), pp. 59f, 102-06, en donde el autor compara la versión de Machado con la de Baudelaire. El juicio de Pimentel sobre la poesía de Machado coincide con la del mismo crítico: J.-M. Massa, A juventude de Machado de Assís (Rio, 1971), p. 414. 
Contra el temido crítico Veríssimo lanza la queja de que no trate con simpatía a los jóvenes:

Il est dommage que José Verissimo soit peu enclin à l'indulgence envers les jeunes, les modernes, et qu'il professe certaines opinions extravagantes.

Ainsi, pour être le seul critique que nous possédions dans le journalisme quotidien, ne prétend-il écrire qu'à propos de livres énormes, volumineux, sans prendre garde aux plaquettes et brochures qu'on peut lui soumettre. (p. 556)

Segundo, censura la dirección de la casa Garnier en el Brasil:

Nous n'avons pas d'éditeurs, parce que les propriétaires de librairies n'entendent rien à ce genre de commerce. La librairie Garnier, succursale de la maison parisienne de la rue des Saints-Pères, est la plus active; mais, outre de payer mal, elle ne sait pas choisir. Elle a ici un gérant, $M$. Lansac, très laborieux, tres aimable, mais qui n'est guère initié aux lettres, qui sait mal notre langue et ne connaît pas le goût de notre public.

$\mathrm{Au}$ lieu d'avoir ici un écrivain brésilien compétent, qui choisisse la matière des éditions, on décide de telles affaires, là-bas même, à Paris, d'après les conseils et l'opinion d'un correspondant de journal, qui n'est pas homme de lettres.

La cuarta y última crónica brasileña, que salió en agosto de 1902, tiene la suerte de acoger uno de los grandes acontecimientos literarios de aquel año ${ }^{54}$ la aparición de Canaã, si bien no menciona para nada el otro, de parecida importancia, la salida de Os sertões de Euclides da Cunha.

Resulta además muy curioso el comentario de Figueiredo Pimentel sobre Graça Aranha:

Dans les cercles littéraires, dans les journaux brésiliens, nul ne connaissait M. Graça Aranha comme écrivain, poète ou prosateur, ni même comme chroniqueur ou journaliste. C'est pourquoi l'étonnement fut grand chez tout le monde, quand on vit, lors de la fondation de notre Académie, entrer ce jeune homme parmi les quarante Immortels. Les mauvaises langues prétendirent que $M$. Graça Aranha devait d'être académicien à sa qualité de Secrétaire de la Légation brésilienne à Londres, et à ses relations auprès des initiateurs de l'Académie.

Pour démontrer la fausseté de telles allégations, M. Graça Aranha vient de faire ses débuts en littérature, avec le roman Chanaan, que publie la librairie Garnier.

\footnotetext{
54 Massaud Moisés, op. cit., p. 18: "a data de 1902 encerra o ciclo en que o Simbolismo mais vigorosamente se impôs no panorama cultural brasileiro". Asimismo, D. S. Loos, op. cit., p. 119, asevera que "a new literary period was definitely established in 1902 with the publication of En. clydes da Cunha's Os sertōes and Graça Aranha's Canaan."
} 
C'est un des plus grands succès littéraires que l'on ait vus au monde, et à coup sûr le plus grand du Brésil. (pp. 543-44)

Se ve debajo de sus palabras cierto resentimiento mal tapado, sin duda porque se trata de un diplomático, especie que Figueiredo Pimentel evidentemente no favorece. Continúa citando y comentando extensamente la entusiasta reseña del Jornal do comércio, "organe bourgeois, anti-littéraire et anti-artistique par excellence", ${ }^{55}$ e intenta asignarle el rango mucho más modesto que a su juicio algo condescendiente le corresponde:

Le romancier de Chanaan n'est pas et ne saurait être "le styliste achevé, maître absolu de tous les secrets de notre belle langue", dont parle le critique en question, non plus que "le penseur profond, qui tire de soi-même les idées grandies dans son sein à la chaleur de la méditation".

A coup sûr, M. Graça Aranha doit devenir un maitre du style, mais plus tard, parce que la forme s'acquiert à force de persévérance.

De la reedición de las Poesías de Olavo Bilac habla con cierto entusiasmo, pero advirtiendo al mismo tiempo que es un poeta que no ha evolucionado nada en veinte años. A Aluízio Azevedo le llama "sans conteste, notre premier romancier" (¿Y Machado de Assis?) y nota la traducción de O livro de uma Sogra al español y la publicación de $A$ Condessa Vesper, versión revisada de Memórias de um Condenado.

En un largo párrafo Figueiredo Pimentel describe otra vez la Academia, acabando con una velada crítica:

Il est hors de doute que la meilleure partie de l'Académie est représentée d'hommes de valeur. Mais qu'a fait et que veut faire

l'Académie de remarquable ou d'utile? (p. 547)

Entonces el cronista se lanza en un misterioso comentario sobre "un pauvre jeune homme, un malade, un hystérique, dont la manie est de vouloir être à toute force un littérateur" (pp. 547-48), que ha fundado una revista en que ha pedido la colaboración de autores naturalistas extranjeros. Se trata sin duda de una estrecha relación personal, difícil hoy de elucidar.

A continuación habla de Pethion de Vilar destacando su calidad de políglota y de director de revista y finalmente comenta algunas revistas francesas dedicadas al Brasil y la Revista contemporânea, nuevamente reaparecida, en la cual tanto Pimentel como Pethion colaboraban. Así termina el primer intento de divulgar los conocimientos sobre literatura brasileña en Francia. Si bien como documentos tienen evidente interés, pecan de cierta falta de selección, de arbitrariedad y de algunos prejuicios personales..$^{56}$

55 Tal fue su inconsecuencia que en la crónica anterior había calificado el mismo periódico "un des plus anciens et des plus grands journeaux du monde entier". (pp. 566-67)

56 He de agradecer a mi colega y amigo John Kinnear varias valiosas indicaciones referentes a las crónicas brasileñas. 
En un homenaje al Mercure, celebrado en 1911 y citado por la Sra. Samurović-Pavlović, Marcel Coulon decía: "Vous ne vous contentez pas d'ouvrir aux écrivains étrangers et à leurs rhapsodes le corps de votre revue. Vous consacrez aux littératures étrangères un bon tiers de votre partie analytique. Lettres allemandes, anglaises, espagnoles, italiennes jusqu'aux tchèques et néerlandaises et celle des Amériques ont leur rubrique attitrée". ${ }^{57}$ Este elogio dirigido a Alfred Vallette me parece un tanto exagerado. Sólo se entiende cuando se tiene en cuenta el grado de exclusivismo corriente en Francia al doblar el siglo: en aquel ambiente la política del Mercure fue relativamente abierta. ${ }^{58} \mathrm{Si}$ bien es verdad que el Mercure estableció, a partir de 1896, la tradición de dar un amplio reportaje extranjero-innovación por la cual merece todo elogio-no se abrían más por eso las páginas específicamente literarias de la revista a la colaboración extranjera. En la época que nos ocupa no había en éstas una sola aportación iberoamericana: una portuguesa y una catalana, con ninguna en lengua española, es la suma ibérica completa. La división resulta, pues, neta e infranqueable: por un lado, crónicas de todas las literaturas extranjeras, en las que libremente se dan informes de lo que pasa en el mundo cultural $;{ }^{59}$ por otro, literatura y creación artística, rígidamente protegida y de un predominio francés abrumador, en cuyas páginas se cuida muy bien de no dejar pasar más que lo aprobado según un criterio selectísimo.

En cuanto a los reportajes hispanoamericanos, empezaron muy bien con crónicas regulares e interesantes según el patrón establecido de una crónica cada tres meses, pero con la partida de Pedro-Emilio Coll quedaron muy mal paradas, condición apenas mejorada cuando por fin Díaz Romero se encargó, de modo deficiente, de la sección. Las letras españolas, que se iniciaron más tarde, tuvieron mayor consistencia y corrieron mejor suerte, llegando a tener, bajo el hispanoamericano Enrique Gómez Carrillo, los méritos positivos de emprender investigaciones y de suscitar polémicas. Y no cabe la menor duda de que estas crónicas despertaron gran interés en todo el mundo hispano-hablante: a los literatos jóvenes, atentos a lo que pasaba en París, las crónicas les ayudaron a enfocar y precisar sus puntos de vista. Mucho más dudoso, me parece, en cambio, el efecto ejercido en Francia, donde parecen haber pasado desapercibidos.

Por lo que se refiere a las crónicas brasileñas, éstas tenían aún más valor informativo que las hispánicas, por ser menos difundidos los conocimientos del

58 Comenta Boyd Carter, op. cit., "el interés que manifestaba Le Mercure de.France, desde un principio, por la cultura de Hispanoamérica, significaba no sólo el tomar en cuenta su nueva literatura modernista, sino también un acto de alta justicia de sentido opuesto a la influencia peyorativa de La Revue des Deux Mondes.

59 Liliana Samurović-Pavlović, op. cit., p. 149, ve como especial mérito de la revista "la liberté absolue d'exprimer leurs opinions, de discuter avec leurs adversaires et de défendre leurs points de vue", pero la libertad de expresión no sirve de mucho cuando la influencia ejercida es tan reducida. 
Brasil y del portugués, pero los escritos de Lebesgue y de Figueiredo Pimentel tienen una calidad indudablemente inferior a los de Coll o de Gómez Carrillo. Por otra parte, parece igualmente cierto que la influencia de estas crónicas hay que ir a buscarla más en Rio o São Paulo que en París.

Las columnas del Mercure de France dieron a unos cuantos latinoamericanos-Coll, Díaz Romero, Gómez Carrillo, Figueiredo Pimentel-una utilísima tribuna en donde desarrollar sus reflexiones sobre la literatura propia, pero conviene tener en cuenta que estas crónicas, escritas en lengua francesa, lejos de·dejar clara huella en el país donde se publicaron, vienen a representar más que nada una continuación de la febril actividad periodística, tan rica y tan significativa, que fue parte imprescindible de la renovación literaria iberoamericana efectuada por aquellas calendas. 
